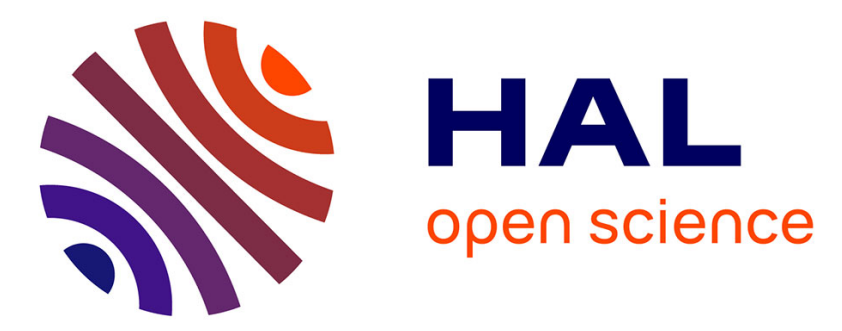

\title{
Olefin Epoxidation by H2O2/MeCN Catalysed by Cyclopentadienyloxidotungsten(VI) and Molybdenum(VI) Complexes: Experiments and Computations
}

Chiara Dinoi, Marco Ciclosi, Eric Manoury, Laurent Maron, Lionel Perrin, Rinaldo Poli

\section{To cite this version:}

Chiara Dinoi, Marco Ciclosi, Eric Manoury, Laurent Maron, Lionel Perrin, et al.. Olefin Epoxidation by $\mathrm{H} 2 \mathrm{O} 2 / \mathrm{MeCN}$ Catalysed by Cyclopentadienyloxidotungsten(VI) and Molybdenum(VI) Complexes: Experiments and Computations. Chemistry - A European Journal, 2010, 3rd European Chemistry Congress, Nürnberg, 16 (31), pp.9572-9584. 10.1002/chem.201000298 . hal-03177754

\author{
HAL Id: hal-03177754 \\ https://hal.science/hal-03177754
}

Submitted on 23 Mar 2021

HAL is a multi-disciplinary open access archive for the deposit and dissemination of scientific research documents, whether they are published or not. The documents may come from teaching and research institutions in France or abroad, or from public or private research centers.
L'archive ouverte pluridisciplinaire $\mathbf{H A L}$, est destinée au dépôt et à la diffusion de documents scientifiques de niveau recherche, publiés ou non, émanant des établissements d'enseignement et de recherche français ou étrangers, des laboratoires publics ou privés. 


\title{
Olefin epoxidation by $\mathrm{H}_{2} \mathrm{O}_{2} / \mathrm{MeCN}$ catalysed by cyclopentadienyloxidotungsten(VI) and molybdenum(VI) complexes: experiments and computations
}

\author{
Chiara Dinoi, ${ }^{[b]}$ Marco Ciclosi, ${ }^{[a]}$ Eric Manoury, ${ }^{[a]}$ Laurent Maron, ${ }^{*[b, c]}$ Lionel Perrin, ${ }^{*[b]}$ and \\ Rinaldo Poli*[a,c]
}

\begin{abstract}
Compounds $\left[\mathrm{Cp}_{2}{ }_{2} \mathrm{M}_{2} \mathrm{O}_{5}\right](\mathrm{M}$ = Mo, 1; $\mathrm{W}, 2)$ are efficient precatalysts for the cyclooctene (COE) epoxidation by aqueous $\mathrm{H}_{2} \mathrm{O}_{2}$ in $\mathrm{MeCN} /$ toluene. The reaction is quantitative, selective and takes place ca. 50 times faster for the $\mathrm{W}$ system $\left(k_{\text {obs }}=4.32(9) \cdot 10^{-4} \mathrm{~s}^{-1}\right.$ at $55^{\circ} \mathrm{C}$ and $3 \cdot 10^{-}$

$3 \mathrm{M}$ concentration for the dinuclear complex, vs. 1.06(7) $10^{-5} \mathrm{~s}^{-1}$ for the Mo system). The rate law is first order in catalyst and COE substrate $(k=$ $0.138(7) \mathrm{M}^{-1} \mathrm{~s}^{-1}$ for the $\mathrm{W}$ system at $55^{\circ} \mathrm{C}$ ), whereas increasing the concentration of $\mathrm{H}_{2} \mathrm{O}_{2}$ slows down the reaction because of an inhibiting effect of the greater amount of water. The activation parameters for the more active $\mathrm{W}$ systems $\left(\Delta \mathrm{H}^{*}=10.2(6) \mathrm{kcal}\right.$ $\mathrm{mol}^{-1} ; \Delta \mathrm{S}^{\ddagger}=-32(2) \mathrm{cal} \mathrm{mol}^{-1} \mathrm{~K}^{-1}$ ) were obtained from an Eyring study in the
\end{abstract}

$25-55^{\circ} \mathrm{C}$ temperature range. The $\mathrm{H}_{2} \mathrm{O}_{2}$.urea adduct was less efficient as an oxidant than the aqueous $\mathrm{H}_{2} \mathrm{O}_{2}$ solution. Replacement of toluene with $\mathrm{Et}_{2} \mathrm{O}$ did not significantly affect the catalyst efficiency, whereas replacement with THF slowed down the process. The epoxidation of ethylene as model olefin catalysed by the $\left[\mathrm{Cp} * \mathrm{MO}_{2} \mathrm{Cl}\right]$ systems $(\mathrm{M}=\mathrm{W}, \mathrm{Mo})$ in the presence of $\mathrm{H}_{2} \mathrm{O}_{2}$ as oxidant and $\mathrm{CH}_{3} \mathrm{CN}$ as solvent has been investigated by DFT calculation with the use of the conductor-like polarisable continuum model (CPCM). For both metal systems, the rate limiting step is the transfer of the hydroperoxido $\mathrm{O}^{\alpha}$ atom to the olefin, in accordance with the first-order dependence on the substrate and the zero order dependence on $\mathrm{H}_{2} \mathrm{O}_{2}$ found experimentally in the catalytic data. The activation barrier corresponding to the rate limiting step is $4 \mathrm{kcal}$ lower for the W complex than for the corresponding Mo analogue (32.3 vs. $28.3 \mathrm{kcal} \mathrm{mol}^{-1}$ ). This result reproduces well the higher catalytic activity of the W species. The different catalytic behaviour between the two systems is rationalised by NBO and NPA analyses. Compared to $\mathrm{Mo}$, the $\mathrm{W}^{\mathrm{VI}}$ center withdraws more electron density from the $\sigma$ bonding $[\mathrm{O}-\mathrm{O}]$ orbital and favours, as a consequence, the nucleophilic attack of the external olefin on the $\sigma^{*}[\mathrm{O}-\mathrm{O}]$ orbital.

Keywords: Molybdenum • Tungsten • Epoxidation catalysis • Hydrogen peroxide $\bullet$ DFT calculations

\section{Dedicated to Prof. Uwe Rosenthal on the occasion of his $60^{\text {th }}$ birthday}

[a] Dr. Marco Ciclosi, Dr. Eric Manoury, Prof. Rinaldo Poli

CNRS; LCC (Laboratoire de Chimie de Coordination); Université de Toulouse; UPS, INPT; 205, route de Narbonne, F-31077 Toulouse Cedex 4, France Fax: (+)33-561553003

E-mail: rinaldo.poli@1cc-toulouse.fr

[b] Dr. Chiara Dinoi, Prof. Laurent Maron, Dr. Lionel Perrin

Laboratoire de Physique et Chimie des Nano-objets, UMR CNRS 5215, 135 Avenue de Rangueil, 31077 Toulouse Cedex 4, France

Fax: (+)33-561559697

E-mail: laurent.maron@insa-toulouse.fr

[c] Prof. Laurent Maron, Prof. Rinaldo Poli

Institut Universitaire de France, 103, bd Saint-Michel, 75005 Paris, France.

Supporting information for this article is available on the WWW under http://www.chemeurj.org/ or from the author. 


\section{Introduction}

Differently from the $\left[\mathrm{Cp}_{2}{ }_{2} \mathrm{Mo}_{2} \mathrm{O}_{5}\right]$ compound, for which several aspects of its aqueous organometallic chemistry have been recently investigated by our group ${ }^{[1-5]}$ the analogue $\mathrm{W}$ complex has been barely investigated in aqueous media. In particular, while high oxidation state cyclopentadienyl Mo-oxido compounds have found large applications in the olefin epoxidation reaction, ${ }^{[6-12]}$ the corresponding cyclopentadienyl $\mathrm{W}$-oxido derivatives have never been tested in this application to the best of our knowledge. However, the well known catalytic activity of several peroxidotungstate systems, often greater than that of molybdenum analogues, ${ }^{[13]}$ as well as the recent progress related to oxotransferase tungsten-containing enzymes ${ }^{[14-20]}$ suggest that the investigation of olefin epoxidations catalyzed by organometallic derivatives of the $\mathrm{WO}_{2}$ fragment could be particularly rewarding. A higher catalytic activity of $\left[\mathrm{Cp}_{2}{ }_{2} \mathrm{~W}_{2} \mathrm{O}_{5}\right]$ compared to the related Mo system has been recently underlined for the oxidation of thiophene derivatives. ${ }^{[21]}$ By using $\mathrm{H}_{2} \mathrm{O}_{2}$ as oxidant in $\mathrm{MeCN}$ solution, the $\mathrm{W}$ compound was found more active than the Mo analogue by a factor of ca. 100 .

These results, as well as the improved and simplified synthetic procedure described for the $\left[\mathrm{Cp}_{2}{ }_{2} \mathrm{~W}_{2} \mathrm{O}_{5}\right]$ complex, ${ }^{[3]}$ encouraged the extension of our investigations to the olefin epoxidation reaction. Concerning the $\mathrm{Cp} * \mathrm{Mo}^{\mathrm{VI}}$-catalysed olefin epoxidation mechanism, some of us have recently reported a computational study in organic and aqueous media using the $\mathrm{Cp} * \mathrm{Mo}(\mathrm{O})_{2} \mathrm{Cl}$ and $\left[\mathrm{Cp}^{*} \mathrm{MoO}_{2}\right]^{+}$ complexes as models for the catalysts and ethylene as model for the substrate. ${ }^{[22]}$ The computed lowest energy pathway involves the formation of an activated hydroxide hydroperoxido intermediate capable of receiving the exogenous nucleophilic attack by the olefin substrate. The study also provided a possible explanation for the lower activity of peroxido derivatives relative to the oxido analogues, as experimentally observed for the $\mathrm{Cp} * \mathrm{Mo}(\mathrm{O})_{2} \mathrm{Cl}$ and $\mathrm{Cp} * \mathrm{MoO}\left(\mathrm{O}_{2}\right) \mathrm{Cl}$ complexes, ${ }^{[23,24]}$ as well as for the lower activity of $\mathrm{H}_{2} \mathrm{O}_{2}$ relative to tert-butylhydroperoxide (THBP). ${ }^{[6]}$ On the basis of our new experimental results and the previous computational work, we extended the computational mechanistic investigation to the olefin epoxidation process catalyzed by the $\mathrm{W}$ system.

\section{Results and Discussion}

\section{(a) Experimental investigations}

The epoxidation of cyclooctene (COE) was studied in a mixture $\mathrm{CH}_{3} \mathrm{CN} /$ toluene $(4 \mathrm{~mL})$ using $\mathrm{H}_{2} \mathrm{O}_{2}$ as oxidant at various temperatures by use of $1 \mathrm{~mol} \%$ of the bimetallic compounds $\left[\mathrm{Cp}^{*}{ }_{2} \mathrm{M}_{2} \mathrm{O}_{5}\right](\mathrm{M}=\mathrm{Mo}, \mathrm{W})$ as precatalysts (i.e., cyclooctene $/$ metal $=$ 50). These conditions are similar to those used in a recent contribution dealing with the catalytic action of the same compounds in the oxidation of thiophene derivatives by $\mathrm{H}_{2} \mathrm{O}_{2} \cdot{ }^{[21]}$ The only difference relative to the previous report is the need of toluene as a co-solvent $(25 \% \mathrm{v} / \mathrm{v})$ in order to insure homogeneous conditions (cyclooctene is not miscible with the $\mathrm{H}_{2} \mathrm{O}_{2}-\mathrm{H}_{2} \mathrm{O}-\mathrm{MeCN}$ phase). Reaction monitoring by gas chromatography revealed the total consumption of the substrate and the final formation of the corresponding epoxide as the sole terminal product, indicating that the reactions are selective and quantitative. The result for one typical run is shown in Figure 1 for the W precatalyst. Figures for all other kinetic runs are given as Supporting Information.

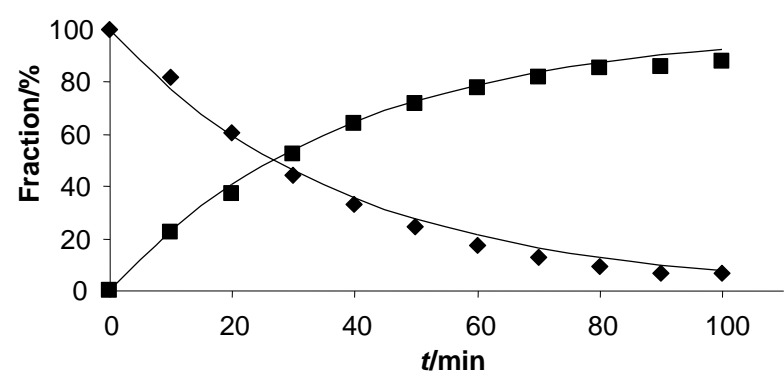

Figure 1. Time dependence of the molar fraction of substrate (diamonds) and epoxide (squares) for the $\mathrm{COE}$ oxidation catalyzed by $\left[\mathrm{Cp}^{*}{ }_{2} \mathrm{~W}_{2} \mathrm{O}_{5}\right]$ using $\mathrm{H}_{2} \mathrm{O}_{2}$ in $\mathrm{MeCN} /$ Toluene $3 / 1$ at $55^{\circ} \mathrm{C}$. The lines are the corresponding fits to first order kinetics (see text).

The reactions took place at convenient rates for GC monitoring in the $25-55^{\circ} \mathrm{C}$ range when using the $\mathrm{W}$ catalyst. As $\left[\mathrm{Cp}^{*}{ }_{2} \mathrm{Mo}_{2} \mathrm{O}_{5}\right]$ is much less active, only one run was carried out at the highest temperature used for the $\mathrm{W}$ analogue. The data fitted well a firstorder rate expression as a function of the substrate concentration, providing the rate constant values collected in Table 1. From an overview of the kinetic data, the $\mathrm{W}$ compound is more active than the Mo compound by a factor of ca. 50 (cf. runs 1 and 2). This activity ratio is similar to that found for the related oxidation of thiophene derivatives under analogous catalytic conditions $\left(k_{\mathrm{W}} / k_{\mathrm{Mo}}\right.$ 100). ${ }^{[21]}$ A remarkable observation is that the Mo system, albeit less active than the $\mathrm{W}$ system, still affords selective epoxidation under these conditions. This observation is in stark contrast with previous reports, where cyclooctene oxidation by $\mathrm{Cp}^{*} \mathrm{Mo}^{\mathrm{VI}}$ catalysts was described as efficient only when using $t \mathrm{BuOOH}$ as an oxidant in a non aqueous solvent, while the addition of water or the use of $\mathrm{H}_{2} \mathrm{O}_{2}$ as an oxidant was reported to give rise to catalyst deactivation. ${ }^{[6]}$

Table 1. Pseudo-first-order rate constants for $\mathrm{COE}$ oxidation by $\mathrm{H}_{2} \mathrm{O}_{2}$ catalyzed by $\left[\mathrm{Cp}_{2}{ }_{2} \mathrm{M}_{2} \mathrm{O}_{5}\right](\mathrm{M}=\mathrm{Mo}, 1 ; \mathrm{W}, 2){ }^{\mathrm{a}}$

\begin{tabular}{|c|c|c|c|c|c|c|c|}
\hline Run & $\begin{array}{l}\text { Solvent } \\
\text { volume }\end{array}$ & {$[\mathrm{COE}](\mathrm{M})$} & $\mathrm{M}$ & Cat/COE & $\mathrm{H}_{2} \mathrm{O}_{2} / \mathrm{COE}$ & $T(\stackrel{\circ}{ } \mathrm{C})$ & $10^{4} k_{\text {obs }}\left(\mathrm{s}^{-1}\right)$ \\
\hline 1 & $4 \mathrm{~mL}$ & 0.3 & Mo & 0.01 & 2 & 55 & $0.106(7)$ \\
\hline 2 & $4 \mathrm{~mL}$ & 0.3 & W & 0.01 & 2 & 55 & $4.32(9)$ \\
\hline 3 & $4 \mathrm{~mL}$ & 0.3 & W & 0.005 & 2 & 55 & $1.79(5)$ \\
\hline 4 & $4 \mathrm{~mL}$ & 0.3 & W & 0.002 & 2 & 55 & $0.70(2)$ \\
\hline 5 & $4 \mathrm{~mL}$ & 0.3 & W & 0.01 & 2 & 45 & $2.29(6)$ \\
\hline 6 & $4 \mathrm{~mL}$ & 0.3 & W & 0.01 & 2 & 35 & $1.45(4)$ \\
\hline 7 & $4 \mathrm{~mL}$ & 0.15 & W & 0.01 & 2 & 25 & $0.81(2)$ \\
\hline 8 & $8 \mathrm{~mL}$ & 0.15 & W & 0.01 & 2 & 55 & $2.43(5)$ \\
\hline 9 & $8 \mathrm{~mL}$ & 0.15 & W & 0.01 & 8 & 55 & $0.74(2)$ \\
\hline 10 & $8 \mathrm{~mL}$ & 0.15 & W & 0.01 & $2+3 \mathrm{v} \mathrm{H}_{2} \mathrm{O}^{\mathrm{b}}$ & 55 & $0.29(2)$ \\
\hline 11 & $4 \mathrm{~mL}$ & 0.3 & W & 0.01 & $2^{\mathrm{c}}$ & 55 & $0.12(4)$ \\
\hline 12 & $4.5 \mathrm{~mL}^{\mathrm{d}}$ & 0.267 & $\mathrm{~W}$ & 0.01 & 2 & 55 & $4.44(11)$ \\
\hline 13 & $4.5 \mathrm{~mL}^{\mathrm{e}}$ & 0.267 & W & 0.01 & 2 & 55 & $1.89(4)$ \\
\hline
\end{tabular}

[a] Solvent $=\mathrm{MeCN} /$ Toluene $(3: 1 \mathrm{v} / \mathrm{v})$ unless otherwise stated. $[\mathrm{b}]$ Additional water $(3$ volume equivalents) was added to the aqueous solution containing 2 mole equivalents of $\mathrm{H}_{2} \mathrm{O}_{2}$ to match the total volume of run 7 (8 mole equivalents of $\mathrm{H}_{2} \mathrm{O}_{2}$ ). [c] $\mathrm{H}_{2} \mathrm{O}_{2}$. urea 


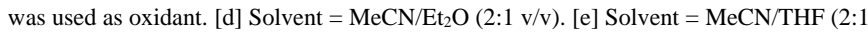
$\mathrm{v} / \mathrm{v})$.

The more active $\mathrm{W}$ system was investigated in the presence of different pre-catalyst amounts (runs 2-4), confirming the first-order dependence of the rate on the catalyst concentration (see Figure 2). From the slope of the straight line the second-order rate constant at $55^{\circ} \mathrm{C}$ could be derived, $k=0.138(7) \mathrm{M}^{-1} \mathrm{~s}^{-1}$. This catalytic system was investigated at several temperatures (runs 2 and 5-7), allowing the determination of the activation parameters through an Eyring analysis, after conversion of the $k_{\text {obs }}$ values to the true second-order rate constant values (Figure 3). The analysis gave $\Delta \mathrm{H}^{+}=10.2(6)$ kcal $\mathrm{mol}^{-1}$ and $\Delta \mathrm{S}^{\ddagger}=-32(2)$ cal $\mathrm{mol}^{-1} \mathrm{~K}^{-1}$. The large negative activation entropy suggests an associative mechanism with a high level of ordering in the transition state relative to the reactants.

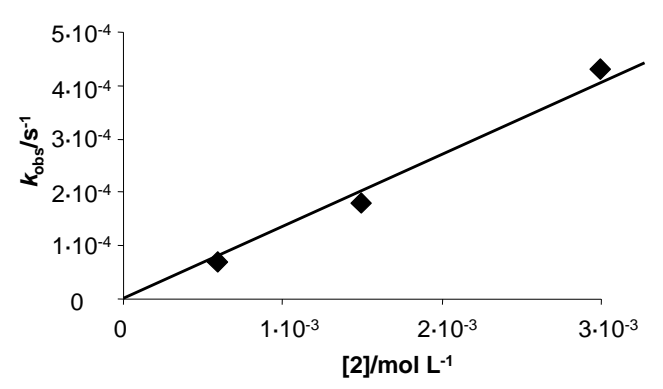

Figure 2. Dependence of observed rate constant on the pre-catalyst concentration.

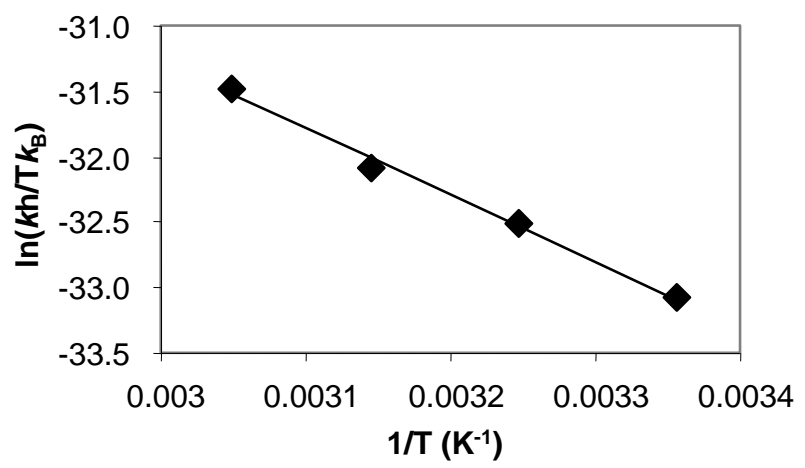

Figure 3. Temperature dependence of the observed rate constant for the $\mathrm{COE}$ epoxidation catalyzed by $\left[\mathrm{Cp}_{2}{ }_{2} \mathrm{~W}_{2} \mathrm{O}_{5}\right]$.

The COE oxidation experiment with the $\mathrm{W}$ catalyst at $55^{\circ} \mathrm{C}$ was run also with different $\mathrm{H}_{2} \mathrm{O}_{2}$ concentrations (runs 8-10). These experiments required higher dilution (half concentration for both substrate and catalyst) in order to avoid phase separation upon addition of the greater amount of the $\mathrm{H}_{2} \mathrm{O}_{2}$ solution. Given the above-determined first-order dependence of the rate on the catalyst concentration, $k_{\mathrm{obs}}$ should decrease by a factor of two for the same $\left[\mathrm{H}_{2} \mathrm{O}_{2}\right] /[\mathrm{COE}]$ ratio, which closely corresponded to the experimental observation ( $c f$. runs 2 and 8). If the rate law had either a first or a zero-order dependence on the oxidant, the observed rate constant should increase or remain constant, respectively, when raising $\left[\mathrm{H}_{2} \mathrm{O}_{2}\right]$. Instead, $k_{\text {obs }}$ decreased by a factor of ca. 6 upon quadrupling $\left[\mathrm{H}_{2} \mathrm{O}_{2}\right]$ ( $c f$. runs 8 and 9). A similar phenomenon was previously observed for the catalyzed oxidation of thiophene derivatives. ${ }^{[21]}$ The hypothesis that the larger excess of $\mathrm{H}_{2} \mathrm{O}_{2}$ partially decomposes the catalyst in run 9 is not supported by the data, because the kinetic model of the first-order reaction still provides an excellent fit of the data and thus indicates that the catalyst does not significantly change in concentration over the time range of the kinetics experiment. It is possible to rationalize this behaviour by invoking a stabilization of the reactant state through hydrogen bonding with the excess water, or by the involvement of other equilibria, favoured by the excess water, between the precatalyst and other complexes, some of which are less active or inactive. The importance of the amount of water in the system (as opposed to the $\mathrm{H}_{2} \mathrm{O}_{2}$ concentration) on the rate was tested in run 10 . In the latter, $\mathrm{a}\left[\mathrm{H}_{2} \mathrm{O}_{2}\right] /[\mathrm{COE}]$ ratio of 2 was maintained, while three additional volume equivalents of pure water were added, in order to have a similar water concentration in runs 9 and 10 (the water amount is actually slightly greater in run 10 because the volume equivalents of the $\mathrm{H}_{2} \mathrm{O}_{2}$ solution that are replaced by pure water contain only $70 \%$ water). The result (slightly lower $k_{\text {obs }}$ for run 10 relative to run 9) confirms that the presence of a big water excess is the cause of the activity decrease, the rate not having a linear dependence on $\left[\mathrm{H}_{2} \mathrm{O}_{2}\right]$.

In an attempt to remove this negative water effect on catalysis, we have tested the stable $\mathrm{H}_{2} \mathrm{O}_{2}$.urea adduct as oxidant (run 11). However, the resulting activity is lower by a factor of 36 than that of the aqueous $\mathrm{H}_{2} \mathrm{O}_{2}$ solution under the same conditions (run 2). The computational section will further explore this point providing, on the basis of the energy profile calculated in the presence of one explicit urea molecule, a rational explanation of this result. Two final experiments were run in different solvents, replacing toluene with $\mathrm{Et}_{2} \mathrm{O}$ (run 12) or THF (run 13). A different solvent combination $(2: 1 \mathrm{v} / \mathrm{v})$ and a slightly greater solvent volume $(4.5 \mathrm{~mL})$ were needed in order to maintain the reaction mixture in a single phase. It is interesting to observe that the rate constant in run 12 is essentially the same as that of run 2, whereas that of run 13 is lower by a factor of ca. 2. THF is a stronger proton acceptor in $\mathrm{H}$-bonding than $\mathrm{Et}_{2} \mathrm{O},{ }^{[25]}$ thus energetically stabilizing the reactant state. This result seems to confirm the above-formulated hypothesis of a H-bonding stabilization effect by the excess water. We can safely conclude that the rate has a first-order dependence on the substrate and a zeroorder dependence on $\mathrm{H}_{2} \mathrm{O}_{2}$. Hence, the substrate is involved in the catalytic cycle between the resting state and the rate-determining transition state, whereas $\mathrm{H}_{2} \mathrm{O}_{2}$ is not.

Before turning to the computational part of this study, we wish to remark here the difference between the results shown here and the previous knowledge on the olefin epoxidation catalyzed by high oxidation state organometallics, all these precedents being related only to Mo. ${ }^{[6-12,23,24,26]}$ Non-aqueous solvents were used for all previous studies in conjunction with $t \mathrm{BuOOH}$ in decane as oxidant. It has been occasionally mentioned that the presence of water impurities poisons the catalyst, ${ }^{7}$ or that the use of $\mathrm{H}_{2} \mathrm{O}_{2}$ results in much reduced catalytic activities or selectivities. ${ }^{[6]}$ In this study, we have shown that although excess water indeed reduces the catalytic activity, its presence does not prevent efficient catalysis, especially for the tungsten system. In fact, the aqueous $\mathrm{H}_{2} \mathrm{O}_{2}$ solution is more efficient than $\mathrm{H}_{2} \mathrm{O}_{2}$.urea in a dry medium.

\section{(b) Computational investigation}

Taking into account the above described experimental data, we extended the recently reported computational study on the $\left[\mathrm{Cp}^{*} \mathrm{MoO}_{2} \mathrm{Cl}\right]$ catalyst $^{[22]}$ to the corresponding $\mathrm{W}$ system. Use of the $\mathrm{Cl}$ atom for the calculations on the Mo system was justified because the chloride complex has indeed been used in experimental 
investigations of epoxidation catalysis, ${ }^{[23]}$ but can also be considered to model the oxido-bridged $\left[\mathrm{Cp} * \mathrm{MoO}_{3}\right]^{-}$group in the $\left[\mathrm{Cp}^{*}{ }_{2} \mathrm{Mo}_{2} \mathrm{O}_{5}\right]$ compound. In the corresponding $\mathrm{W}$ version, we continued to use $\mathrm{Cl}$ as a model anionic ligand for the sake of comparison, even though the known ${ }^{[27]}\left[\mathrm{Cp}^{*} \mathrm{WO}_{2} \mathrm{Cl}\right]$ complex has not been tested as an epoxidation catalyst. The cyclooctene substrate was modelled with the simpler ethylene molecule.

The main goal of this investigation was to rationalize the higher catalytic activity of the $\mathrm{W}$ derivative relative to its Mo analogue. Since the metal change is not expected to dramatically affect the catalytic mechanism, we have initially computed for the $[\mathrm{Cp} * \mathrm{WO} 2 \mathrm{Cl}]$ complex the same path previously outlined for the analogous Mo system. The calculated decrease of the overall activation barrier on going from Mo to $\mathrm{W}$, in agreement with the experiment, will constitute supporting evidence that the mechanism is indeed the same for both systems and a comparison of the calculated and experimentally determined (vide supra) activation parameters will comfort us on the validity of the pathway. In addition, it will be possible to rationalize the metal effect on the catalytic activity upon inspection of the bonding feature at the resting state and rate-determining transition state levels.

The study is mainly divided in five sections. In the first one, we computationally analyze the olefin epoxidation mechanism in the presence of $\mathrm{H}_{2} \mathrm{O}_{2}$ as oxidant and $\mathrm{CH}_{3} \mathrm{CN}$ as solvent, considering the $\left[\mathrm{Cp} * \mathrm{WO}_{2} \mathrm{Cl}\right]$ compound as a model for the dinuclear $\left[\mathrm{Cp}_{2}{ }_{2} \mathrm{~W}_{2} \mathrm{O}_{5}\right]$ complex. The presence of the solvent $\left(\mathrm{CH}_{3} \mathrm{CN}\right)$ has been implicitly considered by performing CPCM continuum model single point and frequency calculations on gas phase optimized geometries. In this approach, the solute molecule, possibly supplemented with some explicit co-solvent water molecules belonging to the first solvation shell, is placed in a cavity surrounded by a polarizable continuum whose reaction field modifies the energy and the properties of the solute. Among the several approaches available for the solvent effect description, continuum models are quite popular ${ }^{[28]}$ since they efficiently account for both the electrostatic and non-electrostatic interaction energy between the solute and the continuum. ${ }^{[29]}$ The second part examines the explicit participation of water molecules in the chemical reaction and in particular the influence of water assistance on the activation barrier heights as well as on the relative energy of the catalytic intermediates. The subsequent section concerns the influence of urea on the energy profile and in particular the presence of a higher energetic barrier for the rate determining olefin epoxidation step. Finally, the fourth and fifth parts computationally rationalize, through an NBO analysis, the different catalytic activities of $\mathrm{W}$ and Mo, providing an explanation for the higher activity of the $\mathrm{W}$ complex relative to its Mo analogue.

The computational study employed the DFT approach with the B3PW91 functional using Stuttgart-Dresden RECPs in association with their polarized basis sets. This level of calculation differs slightly from the approach used in the previous study. ${ }^{[22]}$ Furthermore, while the previous study addressed the catalytic activity in chloroform and used the single-point CPCM in that solvent, the present work investigates the catalytic behaviour of the complexes in $\mathrm{MeCN}$. For these reasons, the previously reported pathway for the Mo catalyst has been recalculated at the same level as the $\mathrm{W}$ system for comparison purposes.

(b1) Olefin epoxidation with $\mathrm{H}_{2} \mathrm{O}_{2}$ in acetonitrile catalyzed by the $\left[\mathrm{Cp}^{*} \mathrm{WO}_{2} \mathrm{Cl}\right]$ system.
In order to check the adequacy of the level of theory used for the coordination properties of $\mathrm{W}$, we first optimized the geometry of the $\left[\mathrm{Cp}_{2}{ }_{2} \mathrm{~W}_{2} \mathrm{O}_{5}\right]$ complex, whose $\mathrm{X}$-ray crystal structure has been recently reported. ${ }^{[3]} \mathrm{A}$ view of the optimized geometry is available in Figure 4 and Table 2 summarizes the main measured and computed geometrical parameters. The remarkable agreement between the experimental and optimized structure traduces the adequacy of the level of theory used to the molecular system studied.

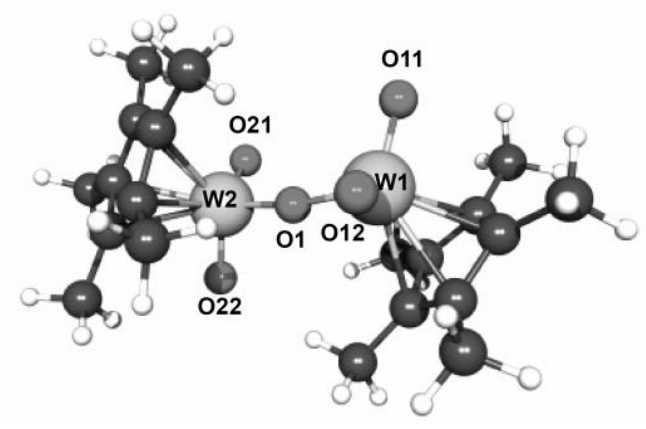

Figure 4. DFT optimized structure of the dinuclear $\left[\mathrm{Cp}^{*}{ }_{2} \mathrm{~W}_{2} \mathrm{O}_{5}\right]$ complex.

The computed energy profile shown in Figure 5 is similar to the one previously reported for the corresponding Mo system. ${ }^{[22]}$ The first step involves the $\mathrm{H}_{2} \mathrm{O}_{2}$ activation with protonation of an oxido ligand, via an initial hydrogen-bonded adduct $\mathbf{2}$ and the transition state ts23. The latter leads to the hydroxido hydroperoxido intermediate 3 . The reaction profile continues with the approach of the olefin to make adduct 4 which, after the hydroperoxido $\mathrm{O}^{\alpha}$ atom transfer to the olefin via ts45, results in the formation of ethylene oxide and complex $\left[\mathrm{Cp}^{*} \mathrm{WCl}(\mathrm{O})(\mathrm{OH})_{2}\right](\mathbf{6})$. The latter regenerates the initial $\left[\mathrm{Cp} * \mathrm{WO}_{2} \mathrm{Cl}\right]$ compound after water elimination. This last step requires an intramolecular proton transfer from one hydroxide ligand to the other one through transition state ts67. According to this energy profile, the resting state of the catalytic cycle is the $\mathrm{H}$ bonded adduct of the $\mathrm{Cp} * \mathrm{WO}_{2} \mathrm{Cl}$ complex with $\mathrm{H}_{2} \mathrm{O}_{2}, 2$, whereas the rate determining transition state is ts45, giving rise to an energy barrier of $28.3 \mathrm{kcal} \mathrm{mol}^{-1}$.

Table 2. Comparison of the DFT-optimized geometry (main distances $[\AA ̊]$, angles $\left[{ }^{\circ}\right]$ ) for the $\left[\mathrm{Cp}_{2}{ }_{2} \mathrm{~W}_{2} \mathrm{O}_{5}\right]$ complex with the X-ray structure of the same compound. ${ }^{\mathrm{a}}$

\begin{tabular}{|c|c|c|c|c|c|}
\hline Bond distances & X-Ray ( & DFT $(\AA)$ & Angles & $\mathrm{X}$-Ray $\left(^{\circ}\right)$ & $\operatorname{DFT}\left({ }^{\circ}\right)$ \\
\hline $\mathrm{W}(1)-\mathrm{O}(1)$ & $1.881(6)$ & 1.900 & $\mathrm{O}(12)-\mathrm{W}(1)-\mathrm{O}(11)$ & $105.2(3)$ & 106.04 \\
\hline $\mathrm{W}(1)-\mathrm{O}(11)$ & $1.729(6)$ & 1.724 & $\mathrm{O}(12)-\mathrm{W}(1)-\mathrm{O}(1)$ & $105.5(3)$ & 104.55 \\
\hline $\mathrm{W}(1)-\mathrm{O}(12)$ & $1.727(6)$ & 1.732 & $\mathrm{O}(11)-\mathrm{W}(1)-\mathrm{O}(1)$ & $104.6(3)$ & 105.67 \\
\hline $\mathrm{W}(1)-\mathrm{CT} 1$ & $2.0993(3)$ & 2.131 & $\mathrm{O}(22)-\mathrm{W}(2)-\mathrm{O}(21)$ & $105.7(4)$ & 106.03 \\
\hline $\mathrm{W}(2)-\mathrm{O}(1)$ & $1.892(6)$ & 1.902 & $\mathrm{O}(22)-\mathrm{W}(2)-\mathrm{O}(1)$ & $104.2(3)$ & 104.55 \\
\hline $\mathrm{W}(2)-\mathrm{O}(21)$ & $1.711(7)$ & 1.724 & $\mathrm{O}(21)-\mathrm{W}(2)-\mathrm{O}(1)$ & $105.7(3)$ & 105.60 \\
\hline $\mathrm{W}(2)-\mathrm{O}(22)$ & $1.732(7)$ & 1.731 & $\mathrm{~W}(1)-\mathrm{O}(1)-\mathrm{W}(2)$ & $170.1(4)$ & 169.69 \\
\hline $\mathrm{W}(2)-\mathrm{CT} 2$ & $2.0957(3)$ & 2.131 & & & \\
\hline
\end{tabular}

[a] Experimental structural data are from ref. ${ }^{[3]}$. 


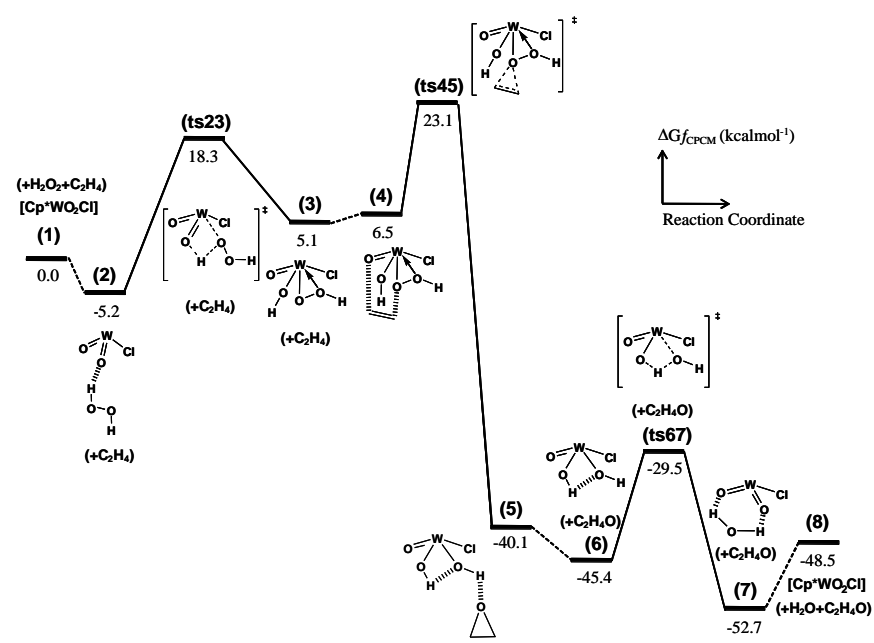

Figure 5. CPCM-corrected free energy profile (in $\mathrm{kcal} \mathrm{mol}^{-1}$ ) for the $\mathrm{H}_{2} \mathrm{O}_{2}$ activation and $\mathrm{C}_{2} \mathrm{H}_{4}$ epoxidation by $\left[\mathrm{Cp} * \mathrm{WO}_{2} \mathrm{Cl}\right]$ in $\mathrm{CH}_{3} \mathrm{CN}$ solution. The reference energy corresponds to the separate reagents $\left(\left[\mathrm{Cp} * \mathrm{WO}_{2} \mathrm{Cl}\right]+\mathrm{H}_{2} \mathrm{O}_{2}+\mathrm{C}_{2} \mathrm{H}_{4}\right)$

The optimized geometries and the main structural data for the key species ts23, 3, 4 and ts45 are shown in Figure 6. The ts 23 structure illustrates the direct intramolecular proton transfer from the $\mathrm{H}_{2} \mathrm{O}_{2}$ molecule, which has already established a significant interaction with the metal atom $(\mathrm{W} \cdots \mathrm{O}=2.292 \AA)$, to the oxo ligand with nearly equivalent $\mathrm{WO} \cdots \mathrm{H}$ and $\mathrm{H} \cdots \mathrm{OOH}$ distances. In order to allow this proton transfer, the $\mathrm{O}-\mathrm{W}-\mathrm{O}$ angle in ts23 must be relatively tight $\left(65.6^{\circ}\right)$, then relaxing to $77.1^{\circ}$ upon going to 3 . This strain may account for the relatively high activation barrier found for this proton transfer process $\left(23.5 \mathrm{kcal} \mathrm{mol}^{-1}\right)$. Complex 3 displays a significant interaction between the hydroperoxido $\beta-\mathrm{O}$ atom and the metal center $\left(\mathrm{W}-\mathrm{O}^{\beta}=2.389 \AA\right.$, W-O ${ }^{\alpha}=2.003 \AA$; W$\mathrm{O}^{\alpha}-\mathrm{O}^{\beta}=85.7^{\circ}$ ) with formation of a strained three-membered $\mathrm{WOO}(\mathrm{H})$ cycle, which is likely to play an important role in the activation of the $\mathrm{O}^{\alpha}$ atom. In this energy profile, the ratedetermining step corresponds to the transfer of the hydroperoxido $\mathrm{O}^{\alpha}$ atom to the olefin (ts45). This result is in agreement with the catalytic data showing a first-order dependence on the substrate. On going from 3 to ts45, the $\mathrm{W}-\mathrm{O}^{\alpha}$ distance lengthens to $2.072 \AA$, the $\mathrm{W}-\mathrm{O}^{\alpha}$ distance shortens to 2.176 , and the $\mathrm{W}-\mathrm{O}^{\alpha}-\mathrm{O}^{\beta}$ angle closes to $68.8^{\circ}$. In order to better compare the calculated and experimental systems we also calculated the absolute CPCM single point $\Delta \mathrm{H}$ enthalpy barrier related to transition state ts45, obtaining a value of $11.5 \mathrm{kcal} \mathrm{mol}^{-1}$ considerably close to the experimental value of 10.2(6) kcal mol-1.
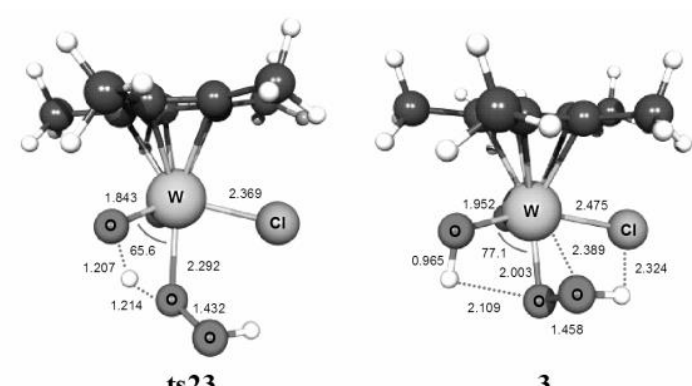

ts 23

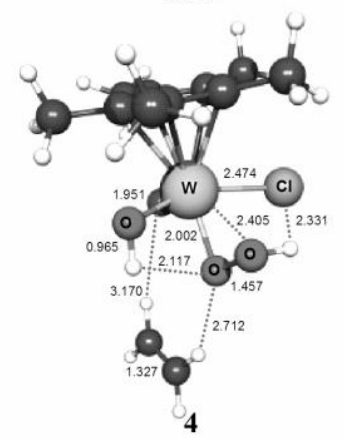

3

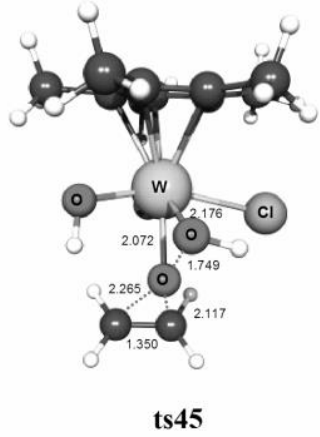

Figure 6. Optimized geometry of systems ts $23,3,4$ and ts45.

\section{(b2) Assisted proton transfer by one water molecule}

In order to further probe the mechanistic details of this reaction, especially regarding the intramolecular proton transfer process involved in transition state ts23, one explicit water molecule was added to the system. Water molecules, which are present in solution together with $\mathrm{H}_{2} \mathrm{O}_{2}$, can facilitate proton-transfer pathways by shuttling the proton since they can establish $\mathrm{H}$ bonds with both the proton donor and the acceptor, as pointed out for other systems. Several theoretical studies have already reported the active participation of water clusters in tautomerisation ${ }^{[30]}$ and protonexchange processes, ${ }^{[5,31]}$ acting as bifunctional catalysts. The energy profile computed with one additional water molecule is shown in Figure 7. In Figure 8, the geometries of the optimized structures are depicted. As shown in Figure 7, the presence of an additional water molecule drives the whole energy profile to a significant energetic stabilization due to the formation of a number of hydrogen bonds. However, the most significant effect is observed at the relative barrier height of ts23a, which is now only $15.8 \mathrm{kcal} \mathrm{mol}^{-1}$ (vs. 23.5 $\mathrm{kcal} \mathrm{mol}^{-1}$ without water). This stabilization is related not only to the ability of the additional water molecule to act, at the same time, as a proton acceptor for the donating $\mathrm{O}-\mathrm{H}$ ligand and as a proton donor for the receiving $\mathrm{O}-\mathrm{H}$ ligand, but also to the smaller distortion of the $\mathrm{O}-\mathrm{W}-\mathrm{O}$ moiety (wider O-W-O angle of $79.3^{\circ}$ in ts23a, see Figure 8 , in comparison with the $65.6^{\circ}$ value optimized for the ts23 structure, Figure 6). The O-W-O angle in ts23a is much closer to that of the proton transfer product $\mathbf{3 a}$, compared to the rearrangement of ts 23 to 3. 


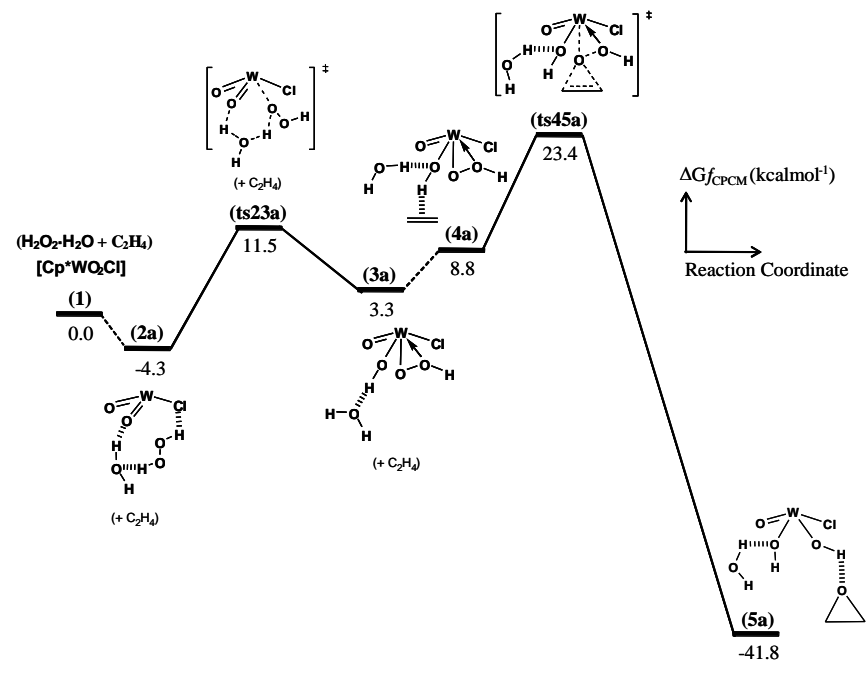

Figure 7. CPCM-corrected free energy profile (in $\mathrm{kcal} \mathrm{mol}^{-1}$ ) for the $\mathrm{H}_{2} \mathrm{O}_{2}$ activation and $\mathrm{C}_{2} \mathrm{H}_{4}$ epoxidation assisted by one water molecule in $\mathrm{CH}_{3} \mathrm{CN}$ solution. The reference energy corresponds to the separate reagents $\left(\left[\mathrm{Cp} * \mathrm{WO}_{2} \mathrm{Cl}\right]+\mathrm{H}_{2} \mathrm{O}_{2}+\mathrm{C}_{2} \mathrm{H}_{4}+\mathrm{H}_{2} \mathrm{O}\right)$.

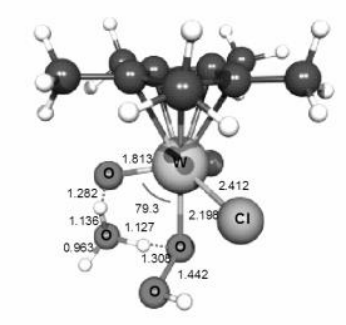

ts23a

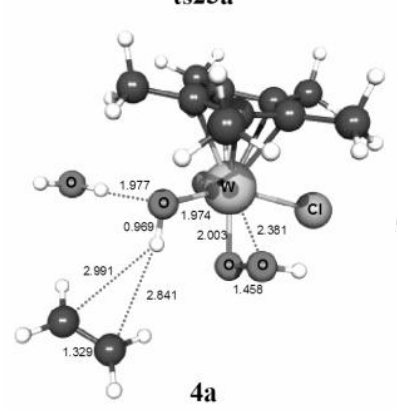

$4 a$

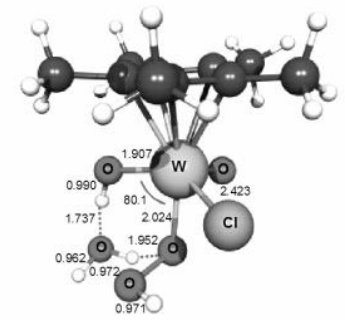

$3 \mathbf{a}$

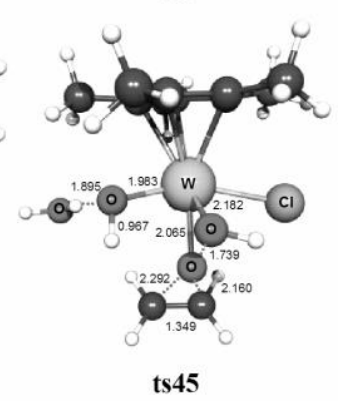

Figure 8. Optimized geometry of systems ts23a, 3a, 4a and ts45a.

Interestingly, the proton that originates from the donating HOO$\mathrm{H}$ group has already migrated onto the water molecule in ts23a $\left(\mathrm{HOO} \cdots\left(\mathrm{HOH}_{2}\right)^{+}\right.$bond $\left.=1.127 \AA\right)$, whereas the proton that eventually ends up in the hydroxido ligand is still bonded to the added water molecule $\left(\left(\mathrm{H}_{2} \mathrm{O}-\mathrm{H}\right)^{+} \ldots \mathrm{O}=1.136 \AA\right)$. As a result, the transition state is better described as a hydronium ion $\left(\mathrm{H}_{3} \mathrm{O}^{+}\right)$ interacting with the anionic $\left[\mathrm{Cp} * \mathrm{WO}_{2} \mathrm{Cl}(\mathrm{OOH})\right]$ molecule through the establishment of two hydrogen bonds with the oxido and hydroperoxo ligands. The assistance of a water molecule leads also to a stabilization of ts45a. The barrier from the resting state (2a) to the rate-determining transition state (ts45a) decreases only slightly to $27.8 \mathrm{kcal} \mathrm{mol}^{-1}$, relative to $28.2 \mathrm{kcal} \mathrm{mol}^{-1}$ for the calculated pathway without added water. For the corresponding CPCM single point enthalpy $\Delta \mathrm{H}$, the value of $12.7 \mathrm{kcal} \mathrm{mol}^{-1}$ for the ratedetermining transition state (ts45a) has been obtained.

The calculated energy difference associated with the $\mathrm{H}_{2} \mathrm{O}_{2}$ activation pre-equilibrium (between systems $\mathbf{2}$ and $\mathbf{3}$ ) is of special interest. The experimental evidence (absence of a first order dependence of the rate law on the $\mathrm{H}_{2} \mathrm{O}_{2}$ concentration, cf. runs 9 and 10 in Table 1) suggests that this pre-equilibrium is shifted toward the hydroperoxido intermediate 3 (i.e. this is the real dormant state of the catalytic cycle) whereas an equilibrium shifted toward $\mathbf{2}$ would entail a first order dependence in $\mathrm{H}_{2} \mathrm{O}_{2}$. The decrease of the energy cost needed to go from $\mathbf{2}$ to $\mathbf{3}, 10.3 \mathrm{kcal} \mathrm{mol}^{-1}$, after adding a water molecule $\left(8.3 \mathrm{kcal} \mathrm{mol}^{-1}\right.$ on going from $\mathbf{2 a}$ to $\left.\mathbf{3 a}\right)$ shows a trend in the correct direction. Under the real conditions of catalysis, a greater amount of water probably interacts with species $\mathbf{2}$ and $\mathbf{3}$, further tipping the balance in favour of the hydroperoxido intermediate.

\section{(b3) Effect of urea}

As shown by the experimental studies, the substitution of water by urea led to a decrease of the reaction rate by a factor of 36 . Taking into account the stronger binding ability of urea as proton acceptor for $\mathrm{H}_{2} \mathrm{O}_{2}$ relative to water, we firstly compared the ability of urea and water in stabilizing the reactant mixture. In a first approximation, we optimised the geometry of the $\mathrm{H}_{2} \mathrm{O}_{2}-\mathrm{H}_{2} \mathrm{O}$ and $\mathrm{H}_{2} \mathrm{O}_{2}-\mathrm{NH}_{2} \mathrm{CONH}_{2}$ adducts (even though both can form extended hydrogen bonding networks in the presence of more solvent molecules) and we calculated the $\Delta \mathrm{G}^{\circ}$ of the exchange reaction reported in Equation 1.

$$
\mathrm{H}_{2} \mathrm{O}_{2} \cdot \mathrm{H}_{2} \mathrm{O}+\mathrm{NH}_{2} \mathrm{CONH}_{2} \rightarrow \mathrm{H}_{2} \mathrm{O}_{2} \cdot \mathrm{NH}_{2} \mathrm{CONH}_{2}+\mathrm{H}_{2} \mathrm{O}
$$

The exoergonicity of this reaction $(-2.66$ and $-3.22 \mathrm{kcal} / \mathrm{mol}$ in the gas phase and in $\mathrm{CH}_{3} \mathrm{CN}$ solution, respectively) indicates that the $\mathrm{H}_{2} \mathrm{O}_{2} \cdot \mathrm{NH}_{2} \mathrm{CONH}_{2}$ system is more stable than the corresponding $\mathrm{H}_{2} \mathrm{O}_{2} \cdot \mathrm{H}_{2} \mathrm{O}$ one. Among the different $\mathrm{H}_{2} \mathrm{O}_{2} \cdot \mathrm{NH}_{2} \mathrm{CONH}_{2}$ and $\mathrm{H}_{2} \mathrm{O}_{2} \cdot \mathrm{H}_{2} \mathrm{O}$ optimised structures, the most stable ones are those shown in Figure 9. ${ }^{[32,33]}$ Both adducts exhibit a cyclic structure that involves two hydrogen bonds.

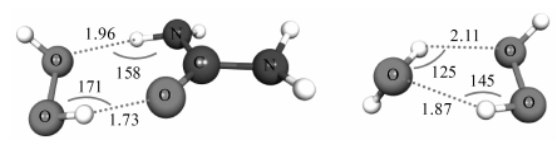

Figure 9. Optimised structures of the most stable $\mathrm{H}_{2} \mathrm{O}_{2} \cdot \mathrm{NH}_{2} \mathrm{CONH}_{2}$ and $\mathrm{H}_{2} \mathrm{O}_{2} \cdot \mathrm{H}_{2} \mathrm{O}$ adducts.

The higher stability of the $\mathrm{H}_{2} \mathrm{O}_{2} \cdot \mathrm{NH}_{2} \mathrm{CONH}_{2}$ adduct is due to its stronger hydrogen bonds, as illustrated by the hydrogen bond lengths and angles reported in Figure 9. The two hydrogen bonds of the $\mathrm{H}_{2} \mathrm{O}_{2} \cdot \mathrm{NH}_{2} \mathrm{CONH}_{2}$ system present length and angle values (1.96, $158^{\circ}$ and $1.73,171^{\circ}$ respectively) compatible with high-strength hydrogen bonds $\left(1.8 \AA\right.$ and $\left.180^{\circ}\right)$. In the $\mathrm{H}_{2} \mathrm{O}_{2} \cdot \mathrm{H}_{2} \mathrm{O}$ adduct, on the other hand, due to the rigidity of the five-membered ring, the bond lengths increased as the angles decreased $\left(2.11,125^{\circ}\right.$ and $1.87,145^{\circ}$ respectively) resulting in hydrogen bond interactions of lower strength compared to those of the $\mathrm{H}_{2} \mathrm{O}_{2} \cdot \mathrm{NH}_{2} \mathrm{CONH}_{2}$ system. The lower catalytic activity observed in the presence of the $\mathrm{H}_{2} \mathrm{O}_{2}$. urea adduct, therefore, may be related to the stronger binding ability of urea for $\mathrm{H}_{2} \mathrm{O}_{2}$ relative to water, stabilizing the reactant mixture by a value of $-3.2 \mathrm{kcal} / \mathrm{mol}$, relative to the rate-determining transition state of the catalytic cycle. In order to verify this point, further probing the mechanistic details of the reaction, the energy profile was calculated in the presence of one explicit urea molecule (Figure 10). Geometries of the optimized structures are depicted in Figure 11. 


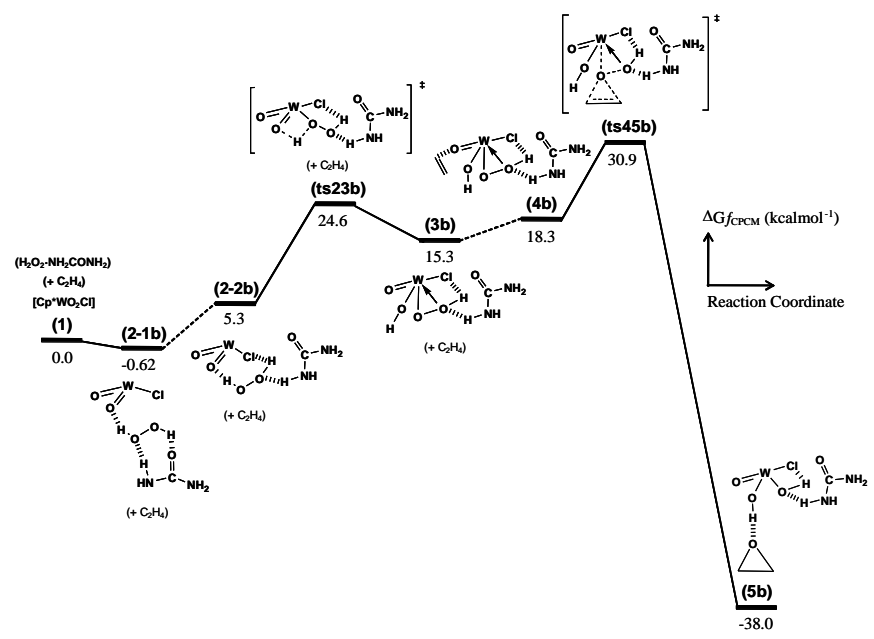

Figure 10. CPCM-corrected free energy profile (in $\mathrm{kcal} \mathrm{mol}^{-1}$ ) for the $\mathrm{H}_{2} \mathrm{O}_{2}$ activation and $\mathrm{C}_{2} \mathrm{H}_{4}$ epoxidation assisted by one urea molecule in $\mathrm{CH}_{3} \mathrm{CN}$ solution. The reference energy corresponds to the separate reagents $\left(\left[\mathrm{Cp} * \mathrm{WO}_{2} \mathrm{Cl}\right]+\mathrm{H}_{2} \mathrm{O}_{2} \cdot \mathrm{NH}_{2} \mathrm{CONH}_{2}+\mathrm{C}_{2} \mathrm{H}_{4}\right)$.
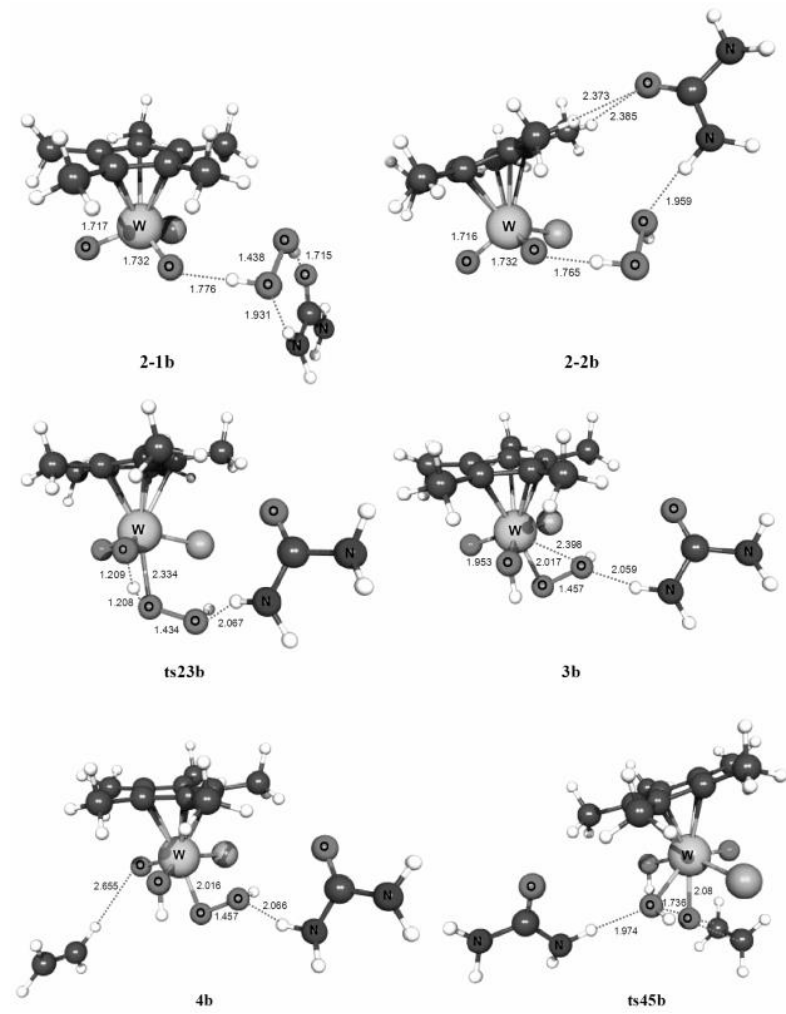

Figure 11. Optimized geometry of systems $\mathbf{2 - 1 b}, \mathbf{2 - 2 b}, \mathbf{t s 2 3 b}, \mathbf{3 b}, \mathbf{4 b}$ and ts45b.

As shown in Figure 11, differently from the water behavior, the urea molecule does not facilitate the proton transfer in the transition state ts23b which requires the same geometry strain previously observed for the water free $\left[\mathrm{Cp} * \mathrm{WO}_{2} \mathrm{Cl}\right]$ catalyzed cycle reported in Figure $6\left(\mathrm{O}-\mathrm{W}-\mathrm{O}=64.9^{\circ}\right.$ in ts23b vs. $\mathrm{O}-\mathrm{W}-\mathrm{O}=76.9^{\circ}$ in $\left.\mathbf{3 b}\right)$. The activation energy barrier corresponding to this step $\left(25.2 \mathrm{kcal} \mathrm{mol}^{-1}\right)$ is very close to that computed for the water free $\mathrm{W}$ system in Figure $5\left(23.5 \mathrm{kcal} \mathrm{mol}^{-1}\right)$. In complex $\mathbf{3 b}$, the hydroperoxo $\beta-\mathrm{O}$ atom is significantly oriented toward the metal center $\left(\mathrm{W}-\mathrm{O}^{\beta}=2.398 \AA\right.$, W$\mathrm{O}^{\alpha}=2.017 \AA$ ), forming a strained three-membered $\mathrm{WOO}(\mathrm{H})$ cycle with a $\mathrm{W}-\mathrm{O}^{\alpha}-\mathrm{O}^{\beta}$ angle of $85.7^{\circ}$. Concerning the rate-determining step, the activation barrier from the resting state (2) to the oxygen transfer step (ts45) is greater in the presence of urea $(31.5 \mathrm{kcal}$ $\left.\mathrm{mol}^{-1}\right)$ than in the presence of water $\left(27.8 \mathrm{kcal} \mathrm{mol}^{-1}\right)$. This result is in accordance with the experimentally observed lower reactivity of the tungsten- $\mathrm{H}_{2} \mathrm{O}_{2}$-urea system compared to the corresponding water analogue.

While the $\mathrm{H}_{2} \mathrm{O}_{2}$.urea compound stabilizes the reactant mixture by ca. $3.2 \mathrm{kcal} / \mathrm{mol}$ compared to the $\mathrm{H}_{2} \mathrm{O}_{2} \cdot$ water system, the adduct $\mathbf{2 - 1 b}$, relative to which the ratedetermining barrier is measured, is $3.7 \mathrm{kcal} / \mathrm{mol}$ higher than the corresponding 2a water complex. The stabilizing effect of urea is thus lost during the coordination of the $\mathrm{H}_{2} \mathrm{O}_{2}$-urea adduct to the metal, indicating that the higher energetic barrier obtained in the presence of urea is not a consequence of the stabilisation of the reactants but it is rather due to the destabilisation of the transition state $\mathbf{t s 4 5 b}$ relative to the water containing ts45a.

\section{(b4) Olefin epoxidation with $\mathrm{H}_{2} \mathrm{O}_{2}$ in Acetonitrile catalyzed by the $\left[\mathrm{Cp}^{*} \mathrm{MoO}_{2} \mathrm{Cl}\right]$ system, 1c.}

In order to directly compare the energetic barriers of the Mo and $\mathrm{W}$ metals and to better understand the effect of the metal on the catalytic activity, the energy profile computed for $\mathrm{W}$ has been recomputed for Mo at the same level of theory (functional, basis set and solvent model, Figure 12). The geometries of the corresponding structures are available as supporting information (Figure S1).

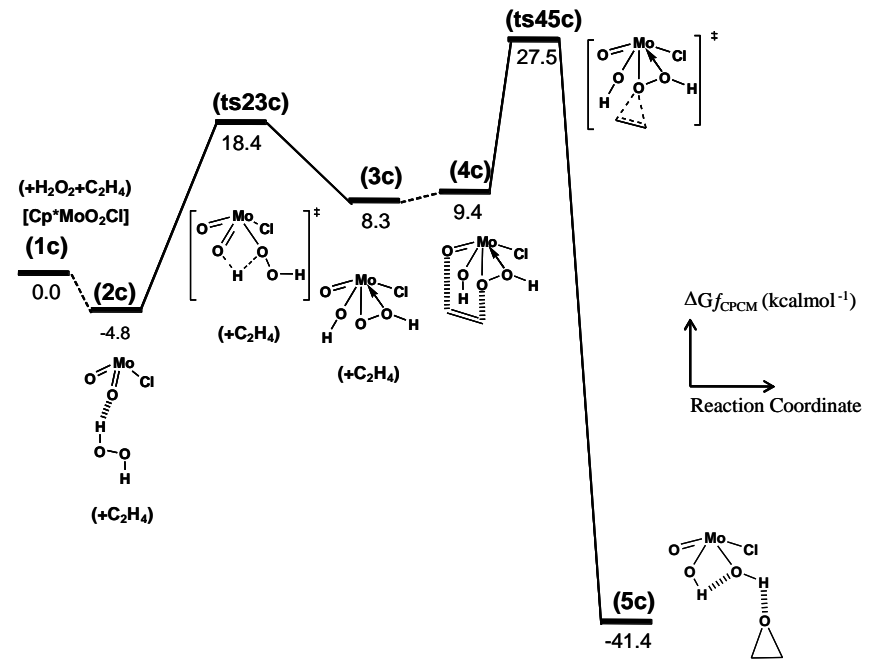

Figure 12. CPCM-corrected free energy profile (in $\mathrm{kcal} \mathrm{mol}^{-1}$ ) for the $\mathrm{H}_{2} \mathrm{O}_{2}$ activation and $\mathrm{C}_{2} \mathrm{H}_{4}$ epoxidation by $\left[\mathrm{Cp} * \mathrm{MoO}_{2} \mathrm{Cl}\right]$ in $\mathrm{CH}_{3} \mathrm{CN}$ solution. The reference energy corresponds to the separate reagents $\left(\left[\mathrm{Cp} * \mathrm{MoO}_{2} \mathrm{Cl}\right]+\mathrm{H}_{2} \mathrm{O}_{2}+\mathrm{C}_{2} \mathrm{H}_{4}\right)$.

In accordance with the experimentally observed lower reactivity of the molybdenum hydroperoxo complex, the rate-determining barrier from the resting state (2c) to the oxygen transfer step (ts45) is greater for Mo $\left(32.3 \mathrm{kcal} \mathrm{mol}^{-1}\right)$ than for $\mathrm{W}\left(28.3 \mathrm{kcal} \mathrm{mol}^{-1}\right)$. A plausible explanation for this behavior and for the specific role of the metal center in the activation/deactivation of the hydroperoxo group will be addressed in the following section. The geometries as well as the bonding parameters of the optimized Mo complexes are very similar to those of the $\mathrm{W}$ analogues described in Figure 6 . The only significant geometrical changes on going from the $\mathrm{W}$ to the Mo system concern the $\mathrm{M}-\mathrm{O}^{\alpha}-\mathrm{O}^{\beta}$ moiety in $\mathbf{3 / 3} \mathbf{c}$ and ts45/ts45c. On going from $\mathbf{3 b}$ to ts45c, the Mo- $\mathrm{O}^{\alpha}$ distance lengthening (to 2.081 $\AA$ ), the Mo- $\mathrm{O}^{\beta}$ distance shortening (to $2.166 \AA$ ), and the $\mathrm{Mo}-\mathrm{O}^{\alpha}-\mathrm{O}^{\beta}$ angle closing (to $68.2^{\circ}$ ) are more pronounced than in the case of $\mathrm{W}$ 
(the corresponding values being $2.072 \AA, 2.176 \AA$ and $68.8^{\circ}$ ), in agreement with a slightly earlier transition state for the $\mathrm{W}$ system.

\section{(b5) Natural Bond Orbital (NBO) analysis of rate-determining transition states.}

The greater activity of tungsten complexes relative to the Mo analogues in the epoxidation reaction has been noted earlier but only limited attention to this phenomenon has been devoted by theoretical studies. ${ }^{[34,35]}$ In order to explain the factors that govern the activity of transition metal hydroperoxido intermediates in olefin epoxidation, and in particular the influence of the metal in activating or deactivating the hydroperoxido group, we carried out an NBO analysis on the $\left[\mathrm{Cp} * \mathrm{M}(\mathrm{O})(\mathrm{OH}) \mathrm{Cl}(\mathrm{OOH})\left(\mathrm{C}_{2} \mathrm{H}_{4}\right)\right](\mathrm{M}=\mathrm{W}$, ts45; $\mathrm{Mo}$, ts45c) transition states. All the possible interactions between "filled" (donor) Lewis-type NBOs and "empty" (acceptor) non-Lewis NBOs have been considered and quantified according to their energetic contribution computed at the $2^{\text {nd }}$-order perturbation analysis.

Concerning the electrophilic character of the oxygen transfer, the NBO analysis reveals a strong overlap between the ethylene $\pi(\mathrm{C}-\mathrm{C})$ and the hydroperoxido unoccupied O-O antibonding orbital, $\sigma^{*}(\mathrm{O}-\mathrm{O})$, for both $\mathbf{t s 4 5}$ and ts45c. The back donation from one of the $\mathrm{O}^{\alpha}$ lone pairs to the $\pi^{*}(\mathrm{C}-\mathrm{C})$ has a much lower contribution to the interaction, demonstrating the electrophilic nature of the oxygen transfer process in the present epoxidation reaction. This is in accordance with previously reported DFT calculations on Mo and W peroxo and diperoxo complexes. ${ }^{[34-40]}$ In addition, the comparison of the $\mathrm{C}_{2} \mathrm{H}_{4} \rightarrow$ [O-O] charge donation for the Mo and $\mathrm{W}$ transition states ts45 and ts45c, shows that the nature of the metal does not directly influence the stabilization energy associated to this interaction. To gain further insights in the driving force of the reaction, we have then analyzed the $\mathrm{M}-[\mathrm{O}-\mathrm{O}]$ orbital interaction. The NBO analysis reveals a strong donation from the occupied $\sigma$ bonding $[\mathrm{O}-\mathrm{O}]$ orbital to the formally empty $\mathrm{d}$ and $\mathrm{p}$ metal orbitals. The involvement of the metal $\mathrm{d}$ and $\mathrm{p}$ orbitals reduces the bonding character of the $\sigma[\mathrm{O}-\mathrm{O}]$ orbital and thus leads to a weakening of the O-O bond. At this point it is important to understand how these interactions between the metal center and the hydroperoxido group vary for different metal centers. By comparing the $[\mathrm{O}-\mathrm{O}] \rightarrow[\mathrm{M}]$ charge donation in both $\mathrm{Mo}$ and $\mathrm{W}$ transition states, we have observed that the corresponding stabilization energy of the donoracceptor interaction computed at the NBO second order of perturbation is considerably higher for $\mathrm{W}$ than for Mo, the associated stabilization energy measuring 82.0 and $31.0 \mathrm{kcal} \mathrm{mol}^{-1}$ respectively. The $\mathrm{W}$ atom, therefore, is likely to attract a higher electron density from the $\sigma$ bonding [O-O] orbital, affording a bigger weakening of the $\mathrm{O}-\mathrm{O}$ bond and consequently lowering the energy of the $\sigma^{*}[\mathrm{O}-\mathrm{O}]$ orbital which is susceptible to the nucleophilic attack by the external olefin.

Another important contribution to the higher catalytic activity of the $\mathrm{W}$ derivative compared to that of Mo belongs to the $\beta$-O atom coordination of the $\mathrm{O}^{\alpha} \mathrm{O}^{\beta}(\mathrm{H})$ moiety to the metal center. For both metals, the NBO second order perturbation analysis reveals a strong overlap between a lone pair localized on the $\beta-O$ atom and the formally empty $\mathrm{d}$ and $\mathrm{p}$ orbitals of the metal. This interaction is stronger for W than for Mo (161.3 vs. $\left.64.2 \mathrm{kcal} \mathrm{mol}^{-1}\right)$, in agreement with the well known higher oxophilic character of $\mathrm{W}$. Hence, the incipient bond formation between the metal and the $\beta-O$ atom withdraws electron density from the bonding [O-O] orbital, lowering consequently the $\sigma^{*}[\mathrm{O}-\mathrm{O}]$ orbital energy and rationalizing the earlier transition state for $\mathrm{W}$ than for Mo, as suggested by the bond parameters (vide supra). On the basis of previous works ${ }^{[37,38]}$ and our NBO analysis, the transition state can be described as two fused three-membered rings in which the metalladioxirane $\mathrm{MO}^{\alpha} \mathrm{O}^{\beta}(\mathrm{H})$ moiety plays a key role in the transfer of the hydroperoxido $\mathrm{O}^{\alpha}$ atom to the olefin (Figure 13). The nature of the metal center strongly influences the electrophilic character of the [O-O] moiety, controlling indirectly the hydroperoxido $\mathrm{O}^{\alpha}$ atom transfer to the olefin. In order to correlate the metal oxophilicity with the charge distribution in the $\left[\mathrm{M}-\mathrm{O}^{\alpha}-\mathrm{O}^{\beta}(\mathrm{H})\right]$ fragment, we carried out a partial charge analysis (NPA) of the two transition states and the two olefin adducts, $\left[\mathrm{Cp} * \mathrm{M}(\mathrm{O})(\mathrm{OH}) \mathrm{Cl}(\mathrm{OOH}) \cdots\left(\mathrm{C}_{2} \mathrm{H}_{4}\right)\right]$ $(\mathrm{M}=\mathrm{W}, \mathbf{4}$; Mo, 4c) that precede them (Figure 13 and Table 3). In agreement with the participation of the metal to the olefin epoxidation reaction, the electrophilic character of the $\left[\mathrm{M}-\mathrm{O}^{\alpha}-\mathrm{O}^{\beta}\right]$ fragment has to be related not just to the $\mathrm{O}^{\alpha}$ charge (almost identical for both compounds), but rather to the sum of the partial charges at the metalladioxirane moiety, $\mathrm{q}(\mathrm{M})+\mathrm{q}\left(\mathrm{O}^{\alpha}\right)+\mathrm{q}\left(\mathrm{O}^{\beta}\right) \cdot{ }^{[37]}$

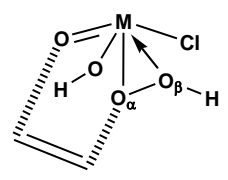

$(4 / 4 c)$

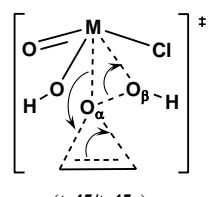

(ts45/ts45c)
Figure 13. The nature of the $\left[\mathrm{Cp} * \mathrm{M}(\mathrm{O})(\mathrm{OH}) \mathrm{Cl}(\mathrm{OOH}) \cdots\left(\mathrm{C}_{2} \mathrm{H}_{4}\right)\right]$ adducts $(\mathrm{M}=\mathrm{W}, 4$; $\mathrm{Mo}$, $4 \mathrm{c})$ and $\left[\mathrm{Cp} * \mathrm{M}(\mathrm{O})(\mathrm{OH}) \mathrm{Cl}(\mathrm{OOH})\left(\mathrm{C}_{2} \mathrm{H}_{4}\right)\right]$ transition states $(\mathrm{M}=\mathrm{W}$, ts45; Mo, ts45c).

Table 3. NPA partial charges of the two transition states and adducts represented in Figure 13.

\begin{tabular}{llllll}
\hline $\mathrm{N}$ & Metal & $\mathrm{q}(\mathrm{M})$ & $\mathrm{q}\left(\mathrm{O}^{\alpha}\right)$ & $\mathrm{q}\left(\mathrm{O}^{\beta}\right)$ & Sum \\
\hline $\mathbf{4}$ & W & 0.97 & -0.35 & -0.41 & 0.21 \\
$\mathbf{4 c}$ & Mo & 0.75 & -0.32 & -0.41 & 0.01 \\
$\mathbf{t s 4 5}$ & W & 0.93 & -0.40 & -0.56 & -0.03 \\
$\mathbf{t s 4 5 c}$ & Mo & 0.70 & -0.39 & -0.56 & -0.24 \\
\hline
\end{tabular}

On going from Mo to $\mathrm{W}$, while the charge at the metal center increases, the charges at the hydroperoxo oxygen atoms are almost identical. The comparison between the Mo and $\mathrm{W}$ systems, therefore, clearly indicates that the $\left[\mathrm{W}-\mathrm{O}^{\alpha}-\mathrm{O}^{\beta}\right]$ fragment is more positive by +0.2 electrons than the Mo analogue. This result well matches the higher electrophilicity of the W-based metalladioxirane system as well as its higher catalytic activity observed both experimentally and computationally.

\section{Conclusions}

The present study constitutes the first report of the activity of a cyclopentadienyltungsten derivative as an epoxidation catalyst. Consistent with a recent report dealing with the oxidation of thiophene derivatives by $\mathrm{H}_{2} \mathrm{O}_{2}$ in $\mathrm{MeCN}$, $\left[\mathrm{Cp}^{*}{ }_{2} \mathrm{~W}_{2} \mathrm{O}_{5}\right]$ has a much greater activity than its Mo analogue under identical conditions (by a factor of 50 in COE epoxidation vs. 100 in the oxidation of benzothiophene). The results of a comparative computational study of the epoxidation pathway for the $\mathrm{W}$ and Mo systems agree with the experimental evidence of the greater activity for the W system. 
The assistance of an additional water molecule drives the whole energy profile to a significant energetic stabilization, lowering in particular the relative barrier height of the $\mathrm{H}_{2} \mathrm{O}_{2}$ activation step. The lower catalytic activity obtained by replacing aqueous $\mathrm{H}_{2} \mathrm{O}_{2}$ with the $\mathrm{H}_{2} \mathrm{O}_{2}$.urea reagent was rationalized on the basis of a transition state destabilization effect, related to the ability of urea to establish stronger hydrogen bonds with $\mathrm{H}_{2} \mathrm{O}_{2}$. Finally, the NBO and NPA analyses have rationalized the greater activity of the $\mathrm{W}$-based catalyst on the basis of the stronger electron density withdrawal from the $\sigma$ bonding $[\mathrm{O}-\mathrm{O}]$ orbital, consequently lowering the energy of the $\sigma^{*}[\mathrm{O}-\mathrm{O}]$ orbital which is susceptible to the nucleophilic attack by the external olefin.

\section{Experimental Section}

Materials and Instrumentation. Cyclooctene (Ega-Chimie), cyclooctene oxide (Fluka), dodecane (Aldrich), and $\mathrm{H}_{2} \mathrm{O}_{2}$ (30\% in water, Fluka) were used as received. Compounds $\left[\mathrm{Cp}_{2}{ }_{2} \mathrm{M}_{2} \mathrm{O}_{5}\right](\mathrm{M}=\mathrm{Mo}, 1 ; \mathrm{W}, 2)$ were prepared as described in the literature ${ }^{[3]} \mathrm{MeCN}$ (SDS, synthesis grade) and Toluene (VWR Prolabo) were used as received. The gas chromatographic analyses were carried out with a Fisons 8000 Series instrument equipped with a SPB-5 capillary column.

General procedure for the catalytic runs. The reactions were carried out in a Schlenk tube with magnetic stirring and held at the chosen temperature by immersion in a thermostated oil bath. The typical experiment was run by charging the tube with the catalyst $\left(1.2 \cdot 10^{-2} \mathrm{mmol}\right)$ followed by $4 \mathrm{~mL}$ of a MeCN/toluene mixture $(3 / 1 \mathrm{v} / \mathrm{v}), 1.2$ mmol of COE $(132 \mathrm{mg}, 156 \mu \mathrm{L})$ and the internal standard (dodecane, ca. $119 \mathrm{mg}, 160$ $\mu \mathrm{L}, 0.7 \mathrm{mmol}$ ). The solution was then warmed to the chosen temperature, followed by dropwise addition of the aqueous $\mathrm{H}_{2} \mathrm{O}_{2}$ solution $(273 \mu \mathrm{L}, 2.4 \mathrm{mmol})$ in 2-3 minutes. The reaction progress was monitored by gas chromatographic analysis of periodically withdrawn samples (ca. $0.2 \mathrm{~mL}$ ), after quenching the excess $\mathrm{H}_{2} \mathrm{O}_{2}$ with $\mathrm{MnO}_{2}$, filtering and diluting with ca. $0.2 \mathrm{~mL}$ of diethyl ether. This allowed the independent measurement, for each sample, of the final epoxide product and the residual COE.

Computational details. Calculations were carried out using Gaussian 03 package at the DFT level by means of the hybrid density functional B3PW91. ${ }^{[41,42]}$ For the W, Mo ${ }^{[43,44]}$ and $\mathrm{Cl}^{[45]}$ atoms, the Stuttgart-Dresden pseudopotentials were used in combination with their associated basis sets augmented by a set of polarization functions (f-orbital polarization exponents of 1.043 and 0.823 for Mo and $\mathrm{W}$ respectively, ${ }^{[46]}$ whereas a dorbital polarization exponent of 0.643 for $\mathrm{Cl}^{[47]}$ ). For the $\mathrm{C}, \mathrm{O}$ and $\mathrm{H}$ atoms the all electron $6-311 \mathrm{G}(\mathrm{d}, \mathrm{p})^{[48]}$ basis sets were used. The nature of the optimized stationary point, minima or transition state, has been verified by means of analytical frequency calculation at $298.15 \mathrm{~K}$ and $1 \mathrm{~atm}$. The geometry optimizations have been achieved without any geometrical constraints. IRC calculations were carried out in order to confirm the connectivity between reactant(s), transition state and product(s). Solvent effects were included implicitly by means of CPCM single point calculations in $\mathrm{CH}_{3} \mathrm{CN}$ $\left(\varepsilon_{\mathrm{r}}=36.64\right)$. The energy data presented correspond to the free enthalpy of the computed compounds in which thermal, vibrational, electrostatic and non-electrostatic contributions have been included. The contribution of the cavitation energy to the solute-solvent interaction energy has been recalculated by the formula of Tunon, ${ }^{[49,50]}$ which more rigorously considers the geometry of the cavity and the occupancy of the solvent molecules inside the cavity (for $\mathrm{CH}_{3} \mathrm{CN}$ at $25^{\circ} \mathrm{C} \gamma=0.0412 \mathrm{kcal} \AA^{-2}, \mathrm{~V}_{\mathrm{s}}=40.31$ $\AA^{3}$, and $\rho=0.015$ molecules $\AA^{-3}$ ). The calculation has been performed using the Pauling atomic radii with explicit hydrogen atoms and the solvent accessible surface (SAS cavity model, which better reproduces the border line between the solute and the solvent. Within the CPCM approximation, the translational and rotational modes are those of the gas phase. The electron density and partial charge distribution in selected transition states were examined in terms of localized electron-pair bonding units by using the NBO program. ${ }^{[51]}$ Through this method, the input atomic orbital basis set is transformed via natural atomic orbitals (NAOs) and natural hybrid orbitals (NHOs) into natural bond orbitals (NBOs), which correspond to the localized one center ("lone pair") and two-center ("bond") elements of the Lewis structure. All possible interactions between "filled" (donor) Lewis-type NBOs and "empty" (acceptor) non-Lewis NBO orbitals, together with their energetic quantification (stabilization energy), has been obtained by a second order perturbation theory analysis of the Fock matrix, as indicated in the NBO program. Only stabilization energy higher than $10 \mathrm{kcal} \mathrm{mol}^{-1}$ has been considered. The NBO program has also been used to perform the natural population analysis (NPA), which affords the natural atomic charges (nuclear charge minus summed natural populations of NAOs on the atom) and total core, valence and Rydberg populations on each atom.

Acknowledgements
We are grateful to the Institut Universitaire de France and the Laboratoire Européen Associé LTPMM (financed by the Centre National de la Recherche Scientifique) for funding and to the Centre Interuniversitaire de Calcul de Toulouse (CICT, Project CALMIP) for granting free CPU time. This work was also performed using HPC resources from GENCI-[CCRT/CINES/IDRIS] (Grant 2009-[c2009086188]). We also gratefully acknowledge a ENASARCO fellowship to CD.

[1] R. Poli, Chem. Eur. J. 2004, 10, 332-341.

[2] E. Collange, F. Demirhan, J. Gun, O. Lev, A. Modestov, R. Poli, P. Richard and D. Saurenz, Results and perspectives of high oxdation state organomolybdenum chemistry in water. In Perspectives in Organometallic Chemistry, Royal Society of Chemistry, London, $\mathbf{2 0 0 3}$ pp. 167-182.

[3] C. Dinoi, G. Taban, P. Sozen, F. Demirhan, J.-C. Daran and R. Poli, J. Organomet. Chem. 2007, 692, 3743-3749.

[4] E. Collange, J. Garcia and R. Poli, New J. Chem. 2002, 26, 1249-1256.

[5] J.-E. Jee, A. Comas-Vives, C. Dinoi, G. Ujaque, V. R. Eldik, A. Lledos and R. Poli, Inorg. Chem. 2007, 46, 4103-4113.

[6] A. M. Martins, C. C. Romão, M. Abrantes, M. C. Azevedo, J. Cui, A. R. Dias, M. T. Duarte, M. A. Lemos, T. Lourenço and R. Poli, Organometallics 2005, 24, 2582-2589.

[7] M. Abrantes, A. Santos, J. Mink, F. Kühn and C. Romão, Organometallics 2003, 22, 2112-2118.

[8] J. Zhao, A. M. Santos, E. Herdtweck and F. E. Kühn, Journal of Molecular Catalysis a-Chemical 2004, 222, 265-271.

[9] J. Zhao, E. Herdtweck and F. E. Kühn, Journal of Organometallic Chemistry 2006, 691, 2199-2206.

[10]C. Freund, M. Abrantes and F. E. Kühn, Journal of Organometallic Chemistry 2006, 691, 3718-3729.

[11] M. Abrantes, A. Sakthivel, C. C. Romão and F. E. Kühn, Journal of Organometallic Chemistry 2006, 691, 3137-3145.

[12]A. M. Al-Ajlouni, D. Veljanovski, A. Capapé, J. Zhao, E. Herdtweck, M. J. Calhorda and F. E. Kühn, Organometallics 2009, 28, 639-645.

[13]B. S. Lane and K. Burgess, Chem. Rev. 2003, 103, 2457-2473.

[14] R. H. Holm, Chemical Reviews 1987, 87, 1401-1449.

[15] S. B. Yu and R. H. Holm, Inorganic Chemistry 1989, 28, 4385-4391.

[16] S. Lee, D. L. Staley, A. L. Rheingold and N. J. Cooper, Inorganic Chemistry 1990, 29, 4391-4396.

[17] A. Cervilla, E. Llopis, A. Ribera, A. Domenech and E. Sinn, Journal of the Chemical Society-Dalton Transactions 1994, 3511-3513.

[18] A. A. Eagle, E. R. T. Tiekink and C. G. Young, Inorganic Chemistry 1997, 36, 6315-6322.

[19] J. P. Donahue, C. Lorber, E. Nordlander and R. H. Holm, Journal of the American Chemical Society 1998, 120, 3259-3260.

[20] G. C. Tucci, J. P. Donahue and R. H. Holm, Inorganic Chemistry 1998, 37, 1602-1608.

[21]M. Ciclosi, C. Dinoi, L. Gonsalvi, M. Peruzzini, E. Manoury and R. Poli, Organometallics 2008, 27, 2281-2286.

[22] A. Comas-Vives, A. Lledós and R. Poli, Chem. Eur. J. 2010, DOI: 10.1002/chem.200902873.

[23] M. B. Trost and R. G. Bergman, Organometallics 1991, 10, 1172-1178.

[24]D. Chakraborty, M. Bhattacharjee, R. Krätzner, R. Siefken, H. W. Roesky, I. Usón and H.-G. Schmidt, Organometallics 1999, 18, 106-108.

[25] A. V. Iogansen, Theor. Experim. Khim., 1971, 7, 302-311.

[26] C. Freund, W. Herrmann and F. E. Kühn, Topics in Organometallic Chemistry 2007, 22, 39-77.

[27] J. W. Faller and Y. Ma, Organometallics 1988, 7, 559-561.

[28] J. Tomasi and M. Persico, Chem. Rev. 1994, 94, 2027-2094.

[29] V. Barone and M. Cossi, Journal of Physical Chemistry A 1998, 102, 1995-2001. 
[30] M. C. P. Lima, K. Coutinho, S. Canuto and W. R. Rocha, Journal of Physical Chemistry A 2006, 110, 7253-7261.

[31]C. Bergquist, B. M. Bridgewater, C. J. Harlan, J. R. Norton, R. A. Friesner and G. Parkin, Journal of the American Chemical Society 2000 , 122, 10581-10590.

[32] J. A. Dobado and J. M. Molina, J. Phys. Chem. 1994, 98, 1819-1825.

[33] J. A. Dobado, J. Molina and D. Portal, J. Phys. Chem. A 1998, 102, 778784.

[34]C. Di Valentin, P. Gisdakis, I. V. Yudanov and N. Rösch, Journal of Organic Chemistry 2000, 65, 2996-3004.

[35]D. V. Deubel, G. Frenking, P. Gisdakis, W. A. Herrmann, N. Rösch and J. Sundermeyer, Accounts of Chemical Research 2004, 37, 645-652.

[36]D. V. Deubel, J. Sundermeyer and G. Frenking, Journal of the American Chemical Society 2000, 122, 10101-10108.

[37]D. V. Deubel, J. Sundermeyer and G. Frenking, European Journal of Inorganic Chemistry 2001, 1819-1827.

[38]D. V. Deubel, Journal of Physical Chemistry A 2001, 105, 4765-4772.

[39]D. V. Deubel, G. Frenking, H. M. Senn and J. Sundermeyer, Chemical Communications 2000, 2469-2470.

[40]I. V. Yudanov, P. Gisdakis, C. Di Valentin and N. Rosch, European Journal of Inorganic Chemistry 1999, 2135-2145.

[41]J. P. Perdew, J. A. Chevary, S. H. Vosko, K. A. Jackson, M. R. Pederson, D. J. Singh and C. Fiolhais, Physical Review B 1992, 46, 6671-6687.

[42] A. D. Becke, J. Chem. Phys. 1993, 98, 5648-5652.

[43]D. Andrae, U. Haussermann, M. Dolg, H. Stoll and H. Preuss, Theoretica Chimica Acta 1990, 77, 123-141.

[44] J. M. L. Martin and A. Sundermann, Journal of Chemical Physics 2001, 114, 3408-3420.

[45] A. Bergner, M. Dolg, W. Kuchle, H. Stoll and H. Preuss, Molecular Physics 1993, 80, 1431-1441.

[46] A. W. Ehlers, M. Boehme, S. Dapprich, A. Gobbi, A. Hoellwarth, V. Jonas, K. F. Koehler, R. Stegmann, A. Veldkamp and G. Frenking, Chemical Physics Letters 1993, 208, 111-114.

[47]L. Maron and C. Teichteil, Chem. Phys. 1998, 237, 105-122.

[48] P. C. Harihara and J. A. Pople, Theoretica Chimica Acta 1973, 28, 213222.

[49]I. Tunon, E. Silla and J. L. Pascualahuir, Chemical Physics Letters 1993, 203, 289-294.

[50] V. Dillet, D. Rinaldi and J. L. Rivail, Journal of Physical Chemistry 1994, 98, 5034-5039.

[51] A. E. Reed, L. A. Curtiss and F. Weinhold, Chem. Rev. 1988, 88, 899926.

Received: ((will be filled in by the editorial staff)) Revised: ((will be filled in by the editorial staff)) Published online: ((will be filled in by the editorial staff)) 
Entry for the Table of Contents

Hydrogen peroxide epoxidation -

Chiara Dinoi, Marco Ciclosi, Eric Manoury, Laurent Maron, * Lionel Perrin* and Rinaldo Poli*

............ Page - Page

Olefin epoxidation by $\mathrm{H}_{2} \mathrm{O}_{2}$ /

MeCN catalyzed by cyclopentadienyloxidotungsten(VI) and molybdenum(VI) complexes: experiments and computations

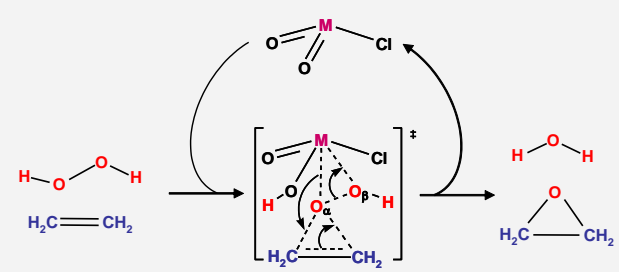

Tungsten is better - Compound difference to the greater oxophilicity $\left[\mathrm{Cp}^{*}{ }_{2} \mathrm{~W}_{2} \mathrm{O}_{5}\right]$ is 50 times more active of tungsten, which plays a than $\left[\mathrm{Cp}_{2}{ }_{2} \mathrm{Mo}_{2} \mathrm{O}_{5}\right]$ for the determining role in the transition quantitative and selective state stabilization. epoxidation of cyclooctene by $\mathrm{H}_{2} \mathrm{O}_{2}$ in MeCN. A DFT study traces this 